poth stratigraphically and culturally. The fourth level of occupation conains a corner-notched projectile point quite similar to the "Pelican ake" culture of Mortlach. Although in-notched basal-thinned points were ound in level No. 8, notched points vere predominant. In fact, notched points were found from top to bottom of the site. Level No. 9-the lowest ound-contained an unusual hafted lade, having a scraping face on one ide and a cutting edige on the other. This has been drawn for you by Dr. Bob Nero.

Geologically speaking, the site epresents successive periods of fornation of top soil by vegetative rowith separated by flood plain leposits. These deposits in the lower evels, from level 5 downward, conain clay and silt layers, representing ccasional lake or ponded water conhitions. Several upper levels contain sravel beds and have received much naterial by slump and slope wash: the buried soil layens are grey or lack and for the most part contain he cultural material since they repesent times when the valley was covered with plant growth and was habitable. A large spring flows through the centre of the site between Project $\mathrm{A}$ and Project $\mathrm{B}$ and must have supplied water to the inhabitants over dozens of centuries.

The site is an important one-not only does it supply us with nine distinct zones of occupation very well separated straitigraphically, but it adds a number of new chapters to the story told at Mortlach. Carbon-14 samples were obtained from five levels of occupation. These samples were pure carbon and are more reliable than the bone submitted for carbon analysis from Mortlach. Many of these artifacts are found for the first time "in situ" in Saskatchewan. The hafted blade will have a carbon date and will help us link the site to similar ones found in the northern plains of United States.

With the excavation and publication of the material from Long Creek site, several new chapters will be added to the history of Saskatchewan.

\title{
Another Petroglyph from Saskatoon
}

by H. K. Cronk, Secretary of the Saskatoon Archaeological Society

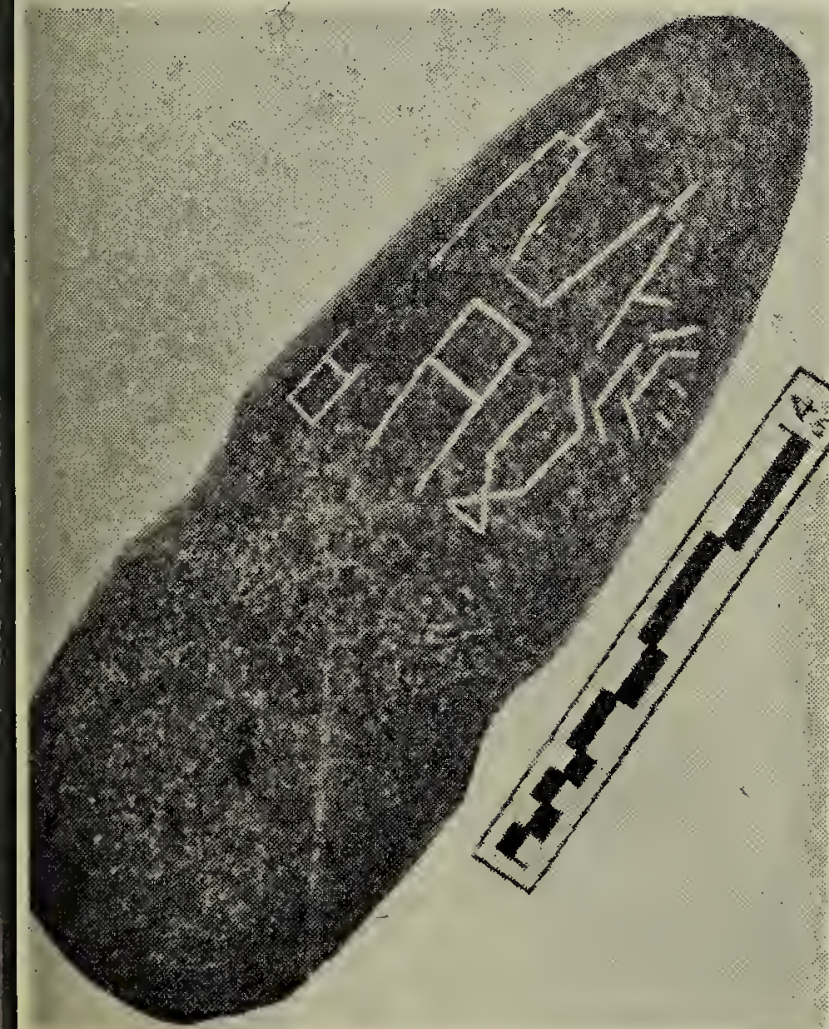

Spade and Screen November 1948, ol. 5, No. 2 published a picture of petroglyph from the collection of he late Dr. Vigfusson, an original nember of the Saskatoon Archaeoagical Society.
Here is a picture of a very rare and interesting find. It is No. 180 in the collection of $E$. L. Bowes of the Saskatoon Society, and was found two miles west of Tisdale on No. 3 highway and a mile south. Petroglyphs are scarce on the prairies, perhaps because collectors are not observant. This picture may stimulate an interest in this type of artifact (petroglyphs). The place to look is on a flat stone. Limestone, being softer, was more easily worked and most petroglyphs are found on that type.

\section{ATTENTION: We need your}

help. If you have any information whatsoever about archaeological sites in the South Saskatchewan River valley from Elbow to the Alberta border please let the Museum know as soon as possible. Information on sites in the valley may help us obtain a programme of archaeolegical salvage work in that area. 